\title{
A Review: Research Status of Plant Growing Concrete
} Zhiqin Zhao ${ }^{\mathrm{a}}$, Zongqinag Zhang, Xiaojun Zhao, Yiqing Ren, Peng Ren

Teaching assistant, Engineering Academy of People's Liberation Army, Xuzhou, China, 221000.

adutzhaozhiqin@foxmail.com

Keywords: Plant Growing concrete, Porous concrete, Alkali environment renovation.

Abstract. Plant Growing concrete (PGC) plays an active role in ecological balance and environmental protection. It had be used in bank slope protection, parking lot, etc. By synthesize research data domestic and overseas, the article reviewed definition , structure, mix proportion, alkali environment renovation, porosity and permeability of PGC, put forward next research fields, had a positive significance on the development and promotion of PGC.

\section{Introduction}

Along with China government is pay more and more attention to environmental protection and biodiversity, as well as the implementation of the strategy of sustainable development . As one of environmental friendly ecological concrete, Plant-Growing Concrete (PGC) caused extensive concern of the industry ${ }^{[1]}$. As we all known, There are many continuous porous inside the concrete so the concrete has good permeability characteristics that suitable for plant growth on the surface, which can greatly improve the surrounding environment of the atmosphere ${ }^{[2]}$.

At the same time, microorganism and small animals can survive on the uneven or continuous gap surface of porous concrete, which can not only maintain the biological diversity, but also purify the water quality, thus has a significant ecological effect $^{[3]}$. In addition, PGC has good mechanical properties; it is widely used in slope protection engineering in Japan, Europe and the United States. However, at present the research work of PGC in China is less, the author synthesize the research achievement of PCG and probe into more application possibility of the concrete ${ }^{[4]}$.

\section{Definition and Structure}

PGC was made of porous concrete, topsoil, water-retention material, nutritive, and plants.PGC used porous concrete as coarse aggregate, and the porous of porous concrete should be continuous. The water-retention material and nutritive filling-in concrete gap, which provide nutrients needed for plant growth. The upper layer was covered by topsoil containing moisture and nutrients promote plant seed germination. Water-retention material and nutritive ensure the plant seedlings growth, the root can reach underlying soil by the continuous porous of porous concrete, which ensures that the further growth of plants. Figure 1 show the structure of porous concrete. Fig. 1 show the structure of PGC. Fig.2 show the structure of porous concrete.

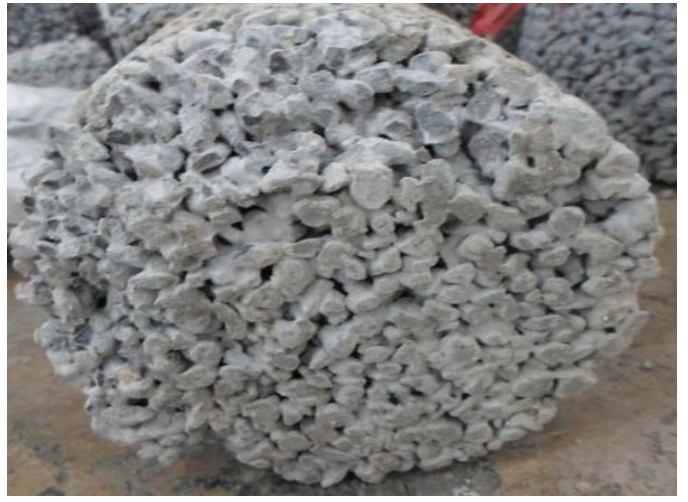

Figure 1 -structure of porous concrete

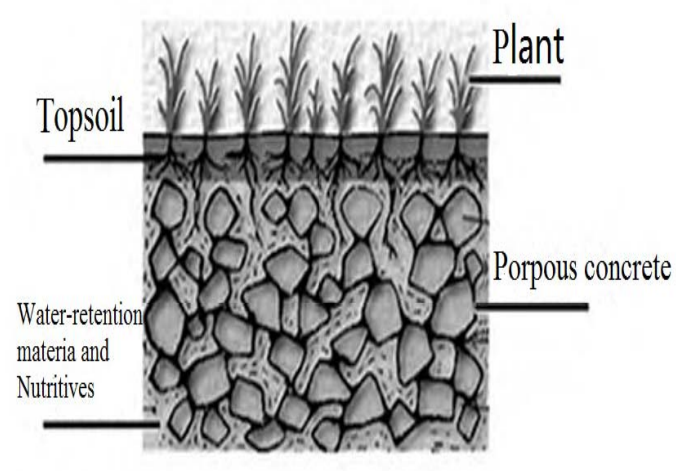

Figure 2 -structure of PGC 


\section{Research Status}

Mix proportion.The major structure of PGC was porous conctet, which was composed of water, cementitious materials, coarse aggregate, water reducer and additional thickener.PGC was different from normal concrete in structure and materials,so the mix design methods was also unlike. For PGC mix proportion, Porosity, permeation coefficient and strength should be taken into account.We can deem the apparent volume of PGC was equal to the Accumulation volume of coarse. So the rual of mix proportion of PGC was using cementitious materials to cover the surface of coarse, which can bond the coarse particle forming a complete and has certain mechanical strength rather than fill the porous among coarse aggregate.

Alkali environment renovation.Along with cement hydration, large amounts of $\mathrm{Ca}(\mathrm{OH})_{2}$ was be produced. $\mathrm{Ca}(\mathrm{OH})_{2}$ was usually in solid form due to the low solubility, which the $\mathrm{PH}$ value within pore was as high as 12 13 that was not suitable for the growth of plants ${ }^{[5]}$. In addition, $\mathrm{Na}+, \mathrm{Ka}+$ and other metal ions were taken in the process of production of cement, which would made sulfate and carbonate that can also produce some basicity. Admixture would also produce some basicity, such as water reducing agent, early strength agent, i.e.. As we all known, Plants can grow only among in a certain scope, so measures should be taken to reduce the PH value in PGC. So the alkali environment renovation in PGC becoming core technology ${ }^{[1,6]}$.

Chao-hui Zhang ${ }^{[7]}$ 's study found that the alkalinity in pore of weak acidic soil was relatively effective just in early around 14 day, but the PH value would return to about 11 later, and the weak acid soil would do long-term negative effects on the strength of porous concrete. Jian-ming Gao ${ }^{[8]}$ used multiple mineral admixtures to lower the $\mathrm{PH}$ value, which found silica fume has the best effect, the $\mathrm{PH}$ value was lower than 10 on 28 day. Gui-ling Wang ${ }^{[8]}$ reached the effect of soaking $\mathrm{FeSO}_{4}$ in soil, which found although the soaking with weak acid material such as $\mathrm{FeSO}_{4}$ can reduce $\mathrm{PH}$ value to about 8 8.5, however, it would decreased the strength remarkable. So the dosage of $\mathrm{FeSO}_{4}$ should not be too much.

Porosity and permeability.Accoring to current research, the suitable porosity of PGC was more than $20 \%$. Generally speaking, PGC's porosity determines the permeability and permeability determine the passivity of water flow ability in PGC, which affect plants survival. The elements that affect porosity and permeability include aggregate size, aggregate grading, aggregate-cement ration and water-cement ration. With aggregate size became smaller or aggregate grading better, porosity , average porous diameter and permeability coefficient became smaller; With aggregate-cement ration increase, porosity and permeability coefficient increase. But reaches had different conclusion on the influence of water-cement ration on porosity and permeability.Zhengqi Li found PGC had good permeability as common soil. Qing-wei Guo ${ }^{[6]}$ thought the permeability increased with the rising of aggregate's size. Wei Zhang hold porosity and permeability increase with water-cement ration decrease. On the contrary, Fei $\mathrm{Xu}^{[7]}$ thought porosity and permeability increase with water-cement ration increase.

purify the water quality. Park and other researcher ${ }^{[1]}$ used silica fume, glass fiber, artificial zeolite and other recycled coarse aggregate to make PGC. They found the PGC can remove total Nitrogen and phosphorus effectively in water desalination, the highest removal rate of total Nitrogen can be to $85.7 \%$, the highest removal rate of total phosphorus can be to $34.9 \%$ 51.6\%. Park found PGC had a good remove effect on phosphorus, and the purification effect was better with the porosity increase, the research result of coarse aggregate with $5 \sim 10 \mathrm{~mm}$ was better than that with 10 20 mm.

Harada $^{[8]}$ through simulate porous concrete's water purification of zinc pollution, found the density of zinc can fall about 50\% 80\%, what's more, they found zinc basic remain in the needle-shaped particles made by cement hydration, which can deduce that physical absorption 
played a leading role in purification process.

Rong-ping $\mathrm{Ji}^{[8]}$ research PGC's effect on the water quality improvement of lake Taihu, the tests indicated that the removal rate of total Nitrogen can be to $36.1 \%$, the removal rate of total phosphorus can be to $53.8 \%$, which means that PGC can really work on Water eutrophication. Yang-hui Chen built simulate river channel and used PGC as river channel, it turn out that the content of total Nitrogen in river dramatic decline.

\section{Application of PGC}

Greening Engineering Project.PGC can be used in roof greening, road greening and side slope greening that was used in large-scale in Japan. Japan set up ecological concrete research committee in 1994, which achieved a lot of achievements, and applied a lot patent, the Apex construction technology center in Japan establish "PGC rival earthwork method" in 2001, which speed up the application of PGC. PGC had been used in Shanghai, Meihekou and Tianjin in China as experimental unit. Fig. 3 display the application of PGC in Japan and China. Fig. 4 show the application of PGC in overflow dam.

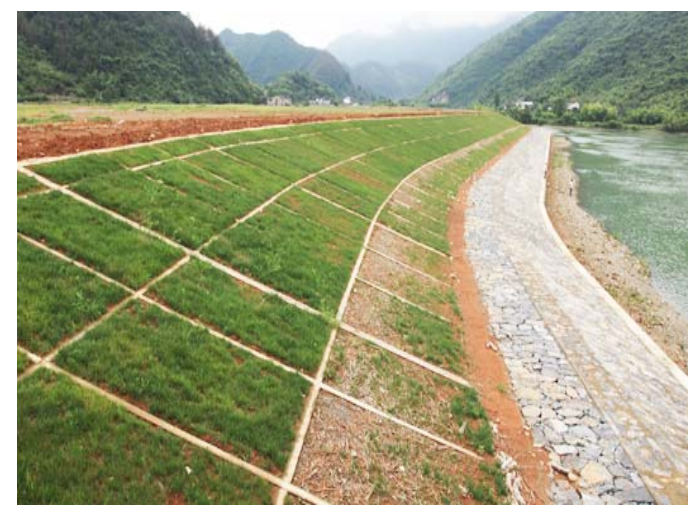

(a)Side slope greening project(Japan)

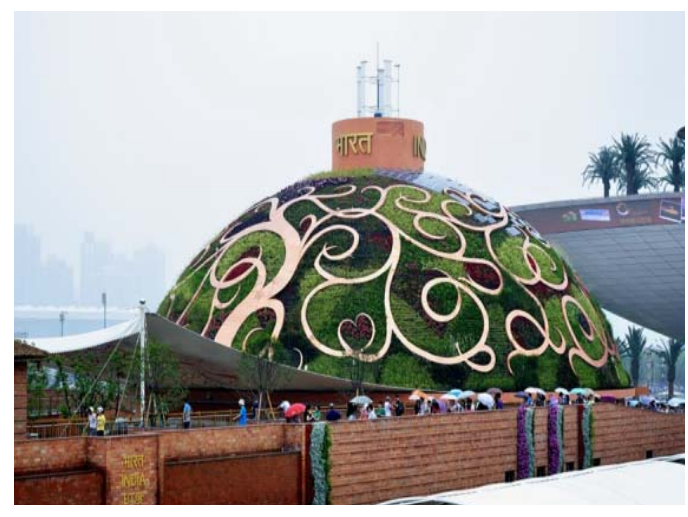

(b) Roof greening project (India building, Expo 2010 in Shanghai)

Fig. 3 -application of PGC

Water Purification Project.PGC can be used to built road, especially in park, housing estate, which not only can take advantage of porous concrete's character to reduce surface runoff, but also can purify the rainfall. It had be used as first bulk filtration in water treatment plant, and used in overflow dam that the running river was eutrophication.

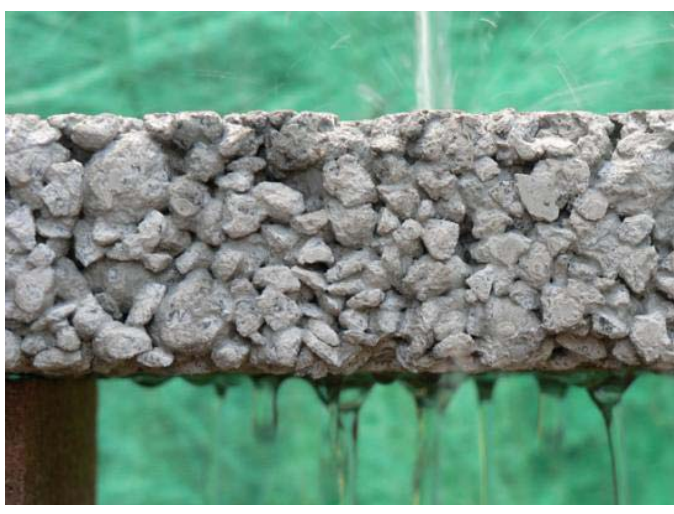

(c)Using in park road project

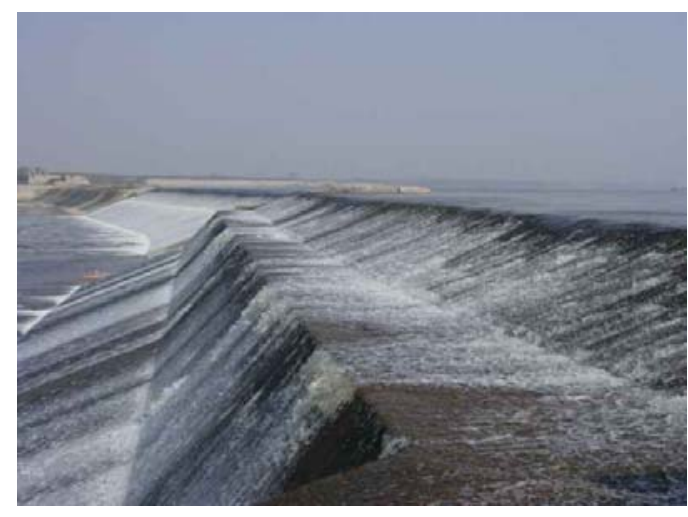

(d) Using in overflow dam

Fig. 4 -application of PGC 


\section{Conclusions}

PGC still in the start stage in China both in theoretical research and practical application, it has great potential and bright prospects. There are some fields we should pay attention in next research. (1)Systematic mix design method;(2)demand of filling soil; mix technology and molding method ;(3) alkali environment renovation method;(4) produce international technical specification.

\section{Acknowledgements}

This research is sponsored by the program of Engineering Academy of People's Liberation Army, Engineering equipment operational application data resources construction.

\section{References}

[1] Liang Zhang, Zhaofang He, Peijun Du,Study on module production method about planting grass eco-concrete[J]. New Building Materials.2014, 41(10). In Chinese

[2] Wang Gui-ling, Wang Long-zhi, Zhang Hai-xia. Meaning,technology index and research emphases of planting eco-concrete[J]. Concrete. 2013(1). In Chinese

[3] Liao Wen-yu, Shi Xian, Huang Zefeng. Study on decreasing alkalinity of planting concrete and the resulting planting effect[J]. Concrete. 2013(7). In Chinese

[4] Wang Yong-hai, Wang Wei, Zhou Yong-xiang. Experimental research on improving measures of plant-growing concrete porous alkaline environment[J]. New Building Materials. 2015, 42(1).

[5] Guo Qing-wei, Hu Yong-you, Zheng Bing-hui. Permeability coefficient chance of planting concrete in different manufacturing stages[J]. Journal of the Chinese Ceramic Society,. 2007, 35(7). In Chinese

[6] Zhang Zheng-ke, Guo Qing-wei, Yan Zhi-yong. Research on community composition in zeolite-vegetation-concrete by PCR-DGGE[J]. China Environment Science. 2013, 33(9). In Chinese

[7] Din Wen-chao, Du Ya-hui, Yu Peng. Research current situation and look into the distance of porous vegetation concrete[J]. Shanxi Architecture. 2014, 40(15). In Chinese

[8] Zhang Shao-biao, Shi Yun-xing, Qu Tie-jun. Research on green-planting concrete and engineering application [J]. Concrete. 2012(8). In Chinese 